Journal of Engineering and Applied Sciences 14 (7): 2262-2267, 2019

ISSN: 1816-949X

(C) Medwell Journals, 2019

\title{
Effect of Sodium Silicate Content on Setting Time and Mechanical Properties of Multi Blend Geopolymer Mortars
}

\author{
${ }^{1}$ Ziyad Kubba, ${ }^{1}$ Esam Hewayde, ${ }^{2}$ Ghasan Fahim Huseien, ${ }^{2}$ Abdul Rahman Mohd Sam and \\ ${ }^{2}$ Mohammad Ali Asaad \\ ${ }^{1}$ Department of Civil Engineering, College of Engineering, Al-Muthanna University, \\ 66001 Samawa, Iraq \\ ${ }^{2}$ Construction Research Center, Institute for Smart Infrastructure and Innovative Construction, \\ Faculty of Civil Engineering, University of Teknologi Malaysia (UTM), \\ 81310 Johor Bahru, Johor, Malaysia
}

\begin{abstract}
The incorporation of industrial waste in geopolymer concrete opens new era in the construction industry because of the positive environmental impact. In this study, the effect of using sodium silicate as an activator on some fresh and hardened properties of geopolymer mortar naming, setting time, workability, density, water absorption, compressive strength, tensile strength and flexural strength were investigated. Industrial waste materials including glass powder, low calcium fly ash, granulated blast furnace slag and ceramic powder were used to prepare specimens of the geopolymer mortars. Results showed that the workability, represented by flow test and water absorption of the geopolymer mortars decreased as the content of the activator (sodium silicate) increased. Both initial and final setting time of the geopolymer mortars were found to be decreased as a response of increasing the content of the activator up to a certain content of the activator. Compressive, tensile and flexural strengths significantly increased as a result of increasing the sodium silicate.
\end{abstract}

Key words: Geopolymer mortar, sodium silicate, workability, compressive strength, flexural strength, water absorption

\section{INTRODUCTION}

Construction industry consumes about $30-40 \%$ of maim energy in the world. Cement industry is the major source of $\mathrm{CO}_{2}$ emission. Hence, different alternatives to conventional concrete are being proposed by researchers to achieve sustainable constructions (Gupta et al., 2016). Geopolymer concretes have emerged as novel engineering materials with the potential to become a substantial element in an environmentally sustainable construction and building products industry (Duxson et al., 2007; Mo et al., 2016; Ng et al., 2012; Provis and Van Deventer, 2009; Sagoe-Crentsil, 2009; Yang et al., 2015). Geopolymer concrete is the result of the reaction of materials containing aluminosilicate with alkalis to produce an inorganic polymer binder. Industrial waste materials such as fly ash and blast furnace slag are commonly used as the source of aluminosilicate for the manufacture of geopolymer concrete due to the low cost and wide availability of these materials. With efficient use of other industrial by products, geopolymer binder can reduce embodied Carbon dioxide $\left(\mathrm{CO}_{2}\right)$ by up to $80 \%$, compared to Ordinary Portland Cement (OPC) (Castel and Foster, 2015).

Alkali-activation is a technology that opens new paths for expanded use of several byproducts already, traditionally, used as mineral additives to cement such as ground Granulated Blast Furnace Slag (GBFS) from steel mills that use a blast furnace to produce pig iron (Deja, 2003; Fernandez-Jimenez et al., 1999; John, 1995; Puertas and Fernandez-Jimenez, 2003) and Fly Ash (FA) from coal-fired power plants (Fernandez-Jimenez et al., 2005; Katz, 1998; Skvara et al., 2003; Sofi et al., 2007). The degree of dissolution of aluminosilicates in high $\mathrm{pH}$ alkaline solutions is largely depend on the particle size, morphology and composition of the source material (Bakharev, 2006; Chen-Tan et al., 2009; Fernandez-Jimenez et al., 2005; Gordon et al., 2005; Jaarsveld et al., 2003) in particular the amorphous aluminosilicates.

Corresponding Author: Ziyad Kubba, Department of Civil Engineering, College of Engineering, Al-Muthanna University, 66001 Samawa, Iraq 
Most of the reports acknowledged that alkaline activator is a mixture of sodium hydroxide $(\mathrm{NaOH})$ in flakes of $98 \%$ purity and sodium silicate $\left(\mathrm{Na}_{2} \mathrm{SiO}_{3}\right)$. Usually, a sodium silicate solution is characterized by its $\mathrm{SiO}_{2} / \mathrm{Na}_{2} \mathrm{O}$ weight ratio in the range of $2-3.75$ where a value $>2.85$ signifies a neutral solution (Pacheco-Torgal et al., 2008). A few researchers used commercial potassium silicate solution with $15.8 \mathrm{wt} . \%$ $\mathrm{K}_{2} \mathrm{O}, 24.2$ wt. $\% \mathrm{SiO}_{2}$ and 60 wt. $\% \mathrm{H}_{2} \mathrm{O}\left(\mathrm{SiO}_{2} / \mathrm{K}_{2} \mathrm{O}\right.$ molar ratio is 2.4 ), potassium hydroxide flakes with $85 \%$ purity and tap water (Obonyo et al., 2011).

The object of this study is to examine the effect of sodium silicate content on fresh and hardened properties of multi blend geopolymer mortar cured at ambient temperature.

\section{MATERIALS AND METHODS}

Multi blend binder included glass powder (WGB), low calcium Fly Ash (FA), Granulated Blast Furnace Slag (GBFS) and ceramic powder (WC). Table 1 shows the chemical composition of materials by using the XRF test. Their XRD and FSEM are shown in Fig. 1 and 2, respectively.

Figure 1 illustrates the XRD patterns of WBG, FA, GBFS and WC. The XRD pattern of WBG and GBFS verifies their highly amorphous nature because of the absence of any sharp peak. One of the most important factors in WBG formation is the reactive silica andalumina content. This high content of reactive
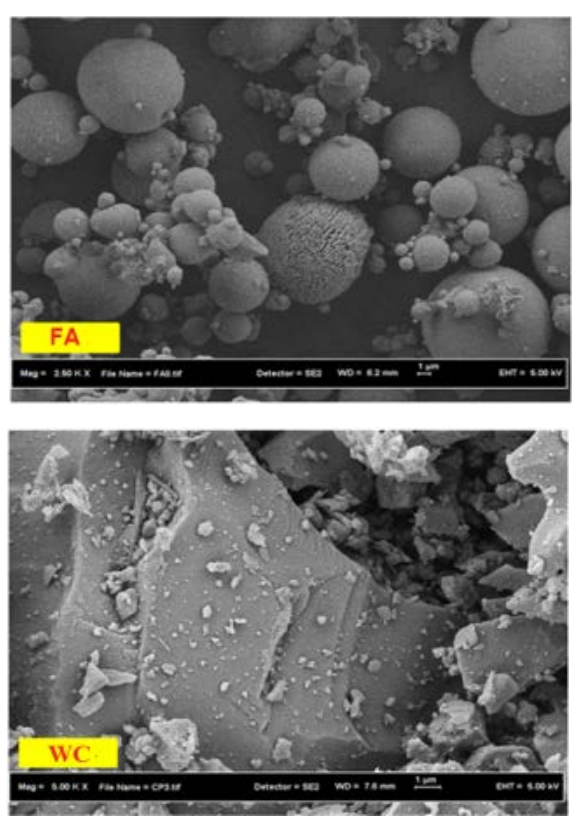

(b)
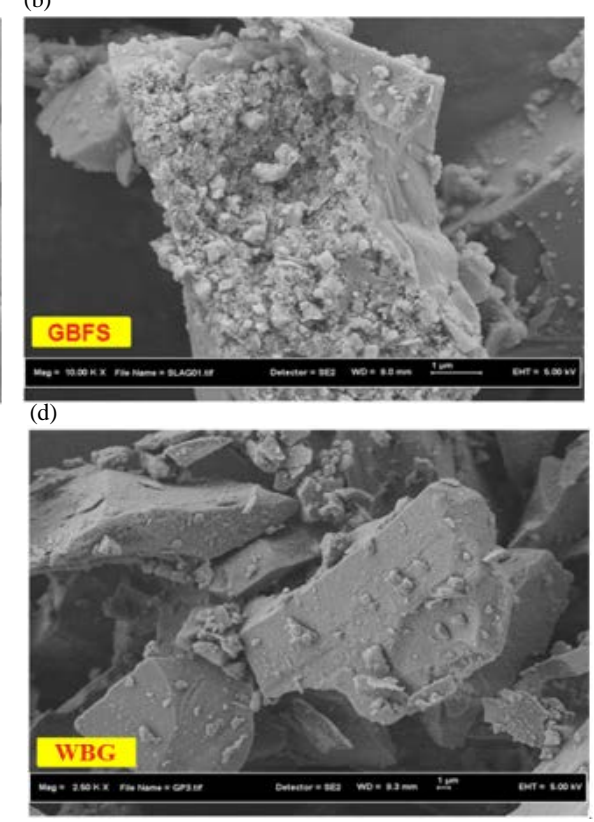

Fig. 2a-d): Scanning Electron Microscopy (SEM)

amorphous silica in WBG is a potential source of silica for GPs preparation. However, incorporation of $\mathrm{FA}$ is required to overcome the low $\mathrm{Al}_{2} \mathrm{O}_{3}$ content $(2.48 \mathrm{wt} . \%)$.

The XRD pattern of FA and WC revealed pronounced diffraction peaks around $2 \theta=16-30^{\circ}$ which are attributed to the crystalline silica and alumina compounds. Nonetheless, the occurrence of other crystalline peaks is ascribed to the presence of crystalline quartz and mullite phases.

\begin{tabular}{|c|c|c|c|c|c|c|c|c|c|}
\hline Material & $\mathrm{SiO}_{2}$ & $\mathrm{Al}_{2} \mathrm{O}_{3}$ & $\mathrm{Fe}_{2} \mathrm{O}_{3}$ & $\mathrm{CaO}$ & $\mathrm{MgO}$ & $\mathrm{K}_{2} \mathrm{O}$ & $\mathrm{Na}_{2} \mathrm{O}$ & $\mathrm{SO}_{3}$ & $\overline{\mathrm{LOI}}$ \\
\hline WBG & 70.57 & 2.48 & 0.28 & 5.59 & 3.05 & 1.35 & 14.49 & 0.19 & 0.95 \\
\hline FA & 57.2 & 28.80 & 3.67 & 5.16 & & 0.94 & 0.08 & 0.10 & 0. \\
\hline GBF & 30.8 & 10. & 0.64 & 51.80 & 4.57 & 0.36 & 0.45 & 0.06 & 0.2 \\
\hline WC & 72.80 & 12.20 & 0.54 & 0.01 & 1.00 & 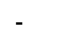 & 13.5 & & \\
\hline
\end{tabular}

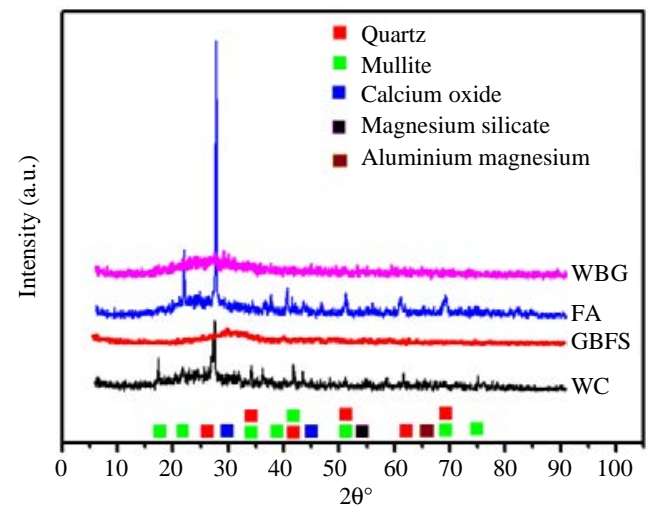

Fig. 1: X-Ray Diffraction (XRD) test of materials used as binder to prepare geopolymer mortar 
Table 2: GPMs Mixtures design with different NS content

\begin{tabular}{llllllll}
\hline Binder & \multicolumn{1}{c}{ Factors } \\
- GBFS & FA & CP & GP & M & S/B & NS $(\%)$ & B/A \\
\hline 55 & 15 & 15 & 15 & 6 & 0.35 & $50-85$ & 1.5 \\
\hline
\end{tabular}

Figures 2 shows the SEM images of FA, GBFS, WC and WBG, respectively which are blended in the GPMs to achieve enhanced comprehensive strength and improved microstructural properties. It is evident that FA consists of spherical particles with smooth surface while the GBFS comprises irregular and angular particles.

Locally available river sand having a specific gravity of 2.74 and passing $100 \%$ of $2.36 \mathrm{~mm}$ sieve was used as fine aggregate for geopolymer mortar mixes. Sodium Hydroxide $(\mathrm{NH})$ prepared with 6 molarity mixed with different ratios of sodium silicate (NS) and used as an alkali activator solution.

Preparation of GPM mixtures: Seven GPM mixtures were prepared with different sodium silicate content $(50,60,65$, 70, 75, 80 and 85). Binder to Aggregate (B:A), Sodium Hydroxide $(\mathrm{NH})$ and the Solution to the Binder (S: B) were fixed with $1.5,8 \mathrm{M}$ and 0.25 for all mixtures in this study as depicted in Table 2 .

Specimen preparation: Mixing was performed in accordance with Standard ASTM (2012). The $50 \mathrm{~mm}$ cube specimens were cast in steel moulds. Binder was added to fine aggregate and mixed for $3 \mathrm{~min}$ to become homogenous followed by solution addition and mixed for other $3 \mathrm{~min}$. Mortar was placed in moulds with 2 layers. Each layer was vibrated by using vibration table for $15 \mathrm{sec}$. Moulds were left in laboratory atmosphere $27^{\circ} \mathrm{C}$ and $75 \%$ humidity for $24 \mathrm{~h}$ before de-moulding. Samples after de-moulding were kept for curing at same condition mentioned above. They were left at ambient temperature till testing date after $1,3,7$ and 28 days.

\section{RESULTS AND DISCUSSION}

Workability: The workability of fresh GPM mixtures is determined using flow test (Anonymous, 2010). Flow test is conducted immediately after mixing. Effects of NS content on the workability of GPMs are inspected. The workability of the mortar is found to be higher at lower NS content. The flow of GPMs is reduced from $24-15 \mathrm{~cm}$ as the NS content is increased from $50-85 \%$, respectively. Figure 3 depicted the effect of NS content on the workability of GPMs. An increase in the NS content is observed to diminish the workability that measured in terms of flow test.

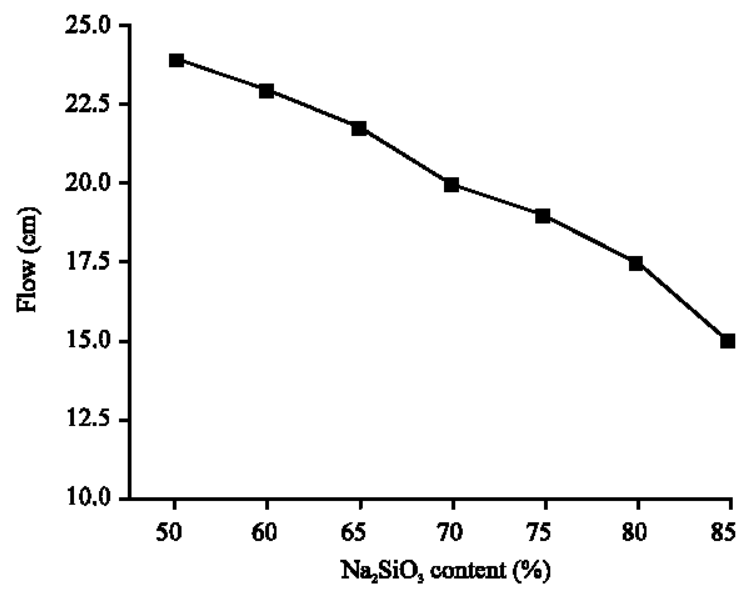

Fig. 3: Effect of NS content on GPMs workability

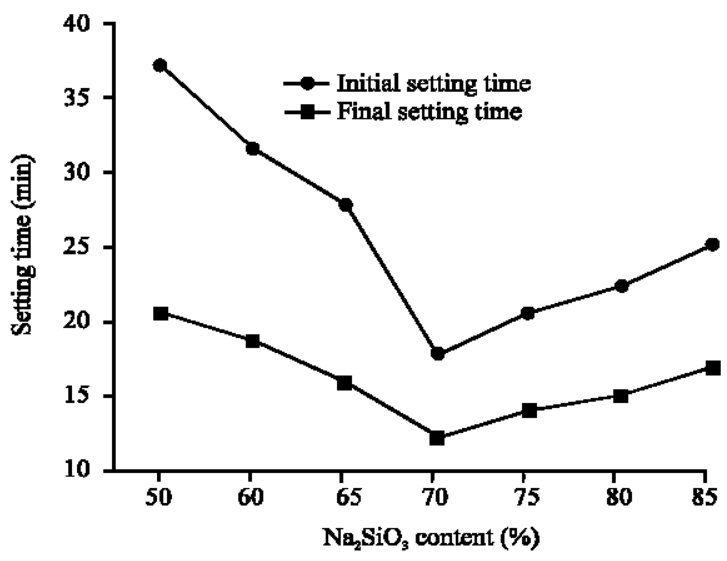

Fig. 4: GPMs setting time with different NS content

Setting time: Setting time of GPMs is tested at room temperature $\left(27^{\circ} \mathrm{C}\right)$ following ASTM C191 standard. The mortar is prepared manually by mixing the binders and the alkaline solutions in a bowl and tested for setting time using Vicat apparatus. The GPMs activated at low NS content took significantly longer time to set due to slow rate of chemical reaction at low ambient temperature. The influence of NS content on the setting time of GPMs is presented in Fig. 4. It can be concluded from Fig. 4, that the GPM mixtures that are prepared with $70 \%$ content of NS revealed very fast setting time. The GPMs setting time is improved considerably with the reduction of $\mathrm{NH}$ content and increase NS content from $70-85 \%$. It can also be concluded from Fig. 4 that both initial and final setting time is enhanced when NS content was more than $70 \%$. Furthermore, the rate of setting is increased appreciably as indicated by the substantial difference in the initial setting time. The difference between initial and final setting time is also increased with the reduction of NS content $<70 \%$ in the mortar. 


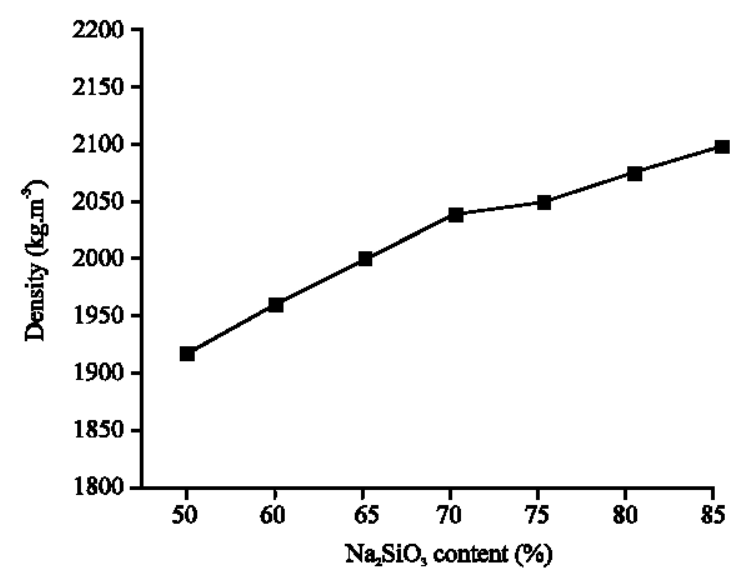

Fig. 5: GPMs density with different NS content

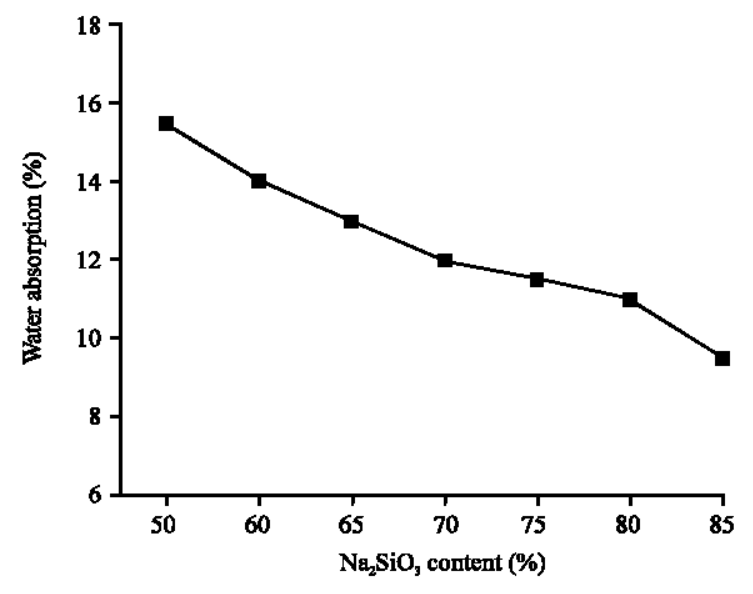

Fig. 6: Effect of NS content on GPMs water absorption

Density: Figure 5 demonstrates the variation of GPMs density as a function of NS content. An increase in the mortars density with increasing NS content is attributed to the compactness of the network structures. At lower NS content the microstructures are less dense and the flow is easier. However, with the increase of NS content the structural network of the GPMs becomes denser that caused a reduction in the flow as well as overall setting time.

Water absorption: The results of water absorption are presented in Fig. 6. Results revealed that water absorption decreasedwith increase in sodium silicate content. On the other hand, an increase in the NS content affected the geopolymerization system and increase the dissolution of $\mathrm{Si}$ and $\mathrm{Al}$ and led to enhance the GPM microstructure and reduce the porous. The same conclusion was reported by Al Bakri Abdullah et al. (2012).

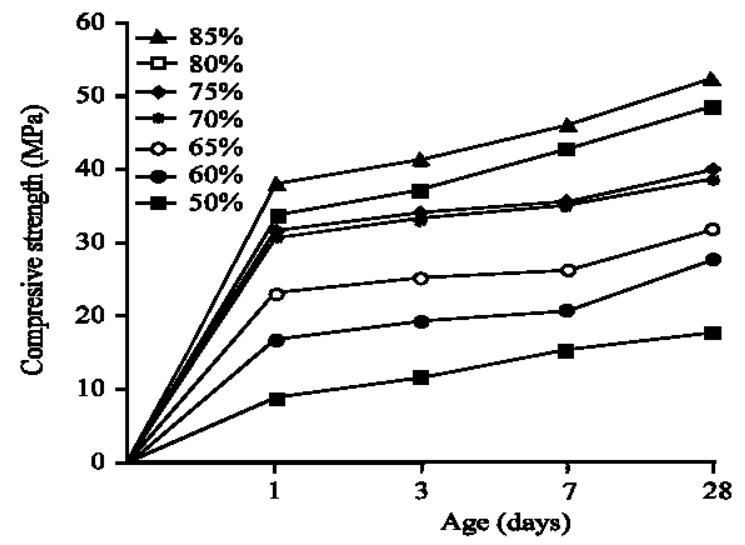

Fig. 7: The NS content effect of GPMs compressive strength

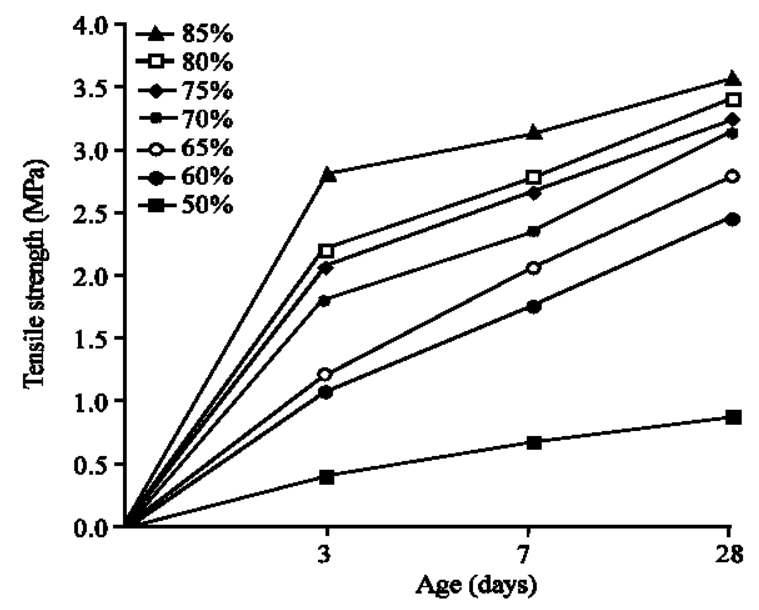

Fig. 8: Effect of NS content of GPMs tensile strength

Compressive strength: Figure 7 shows the effect of NS content on the compressive strength of GPMs ages for different durations. GPMs with $50 \%$ NS content revealed the lowest value of compressive strength (below $21 \mathrm{MPa}$ ). The mixture with $60 \% \mathrm{NS}$ content displayed a compressive strength of $19.8,21.3,23.6$ and 29.1 MPa at age of 1, 3, 7 and 28 days, respectively which is higher than GPM prepared with $50 \%$ NS content. The increase in compressive strength and density of GPMs with increasing NS content is in fact correlated (Fig. 6). On the other hand, the increase sodium silicate content accelerates the geopolymerization operation and increase the dissolution of $\mathrm{Si}$ and $\mathrm{Al}$ and enhance the microstructure of GPMs.

Tensile strength: The effect of NS content on tensile strength of GPMs was evaluated after 3,7 and 28 days. Figure 8 shows the tensile strength of samples activated 


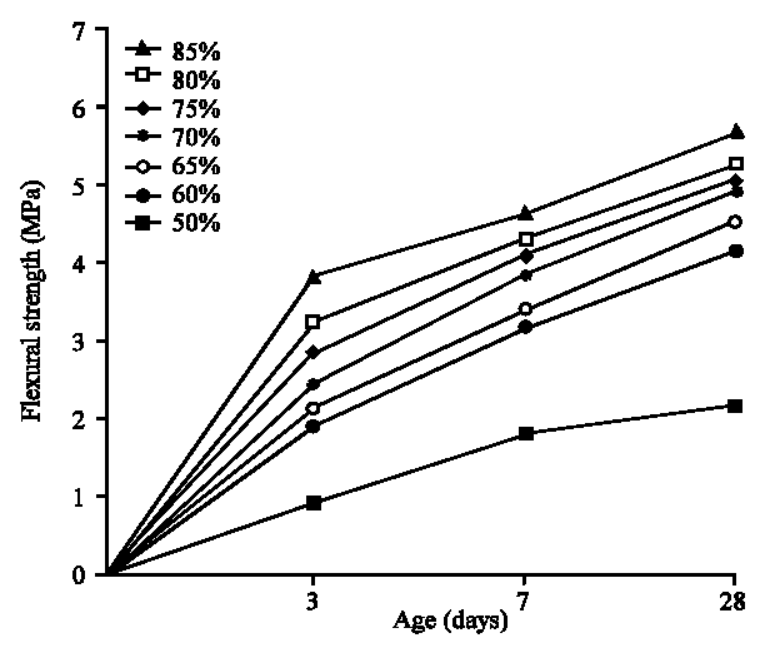

Fig. 9: Effect of NS content of GPMs flexural strength

by different NS content. The effects of increasing NS content were investigated. It is observed that the activation of GBFS by alkali could dissolve $\mathrm{Ca}$ whereas Si and Al participated to create $\mathrm{CSH}$ and $\mathrm{CASH}$ gel, thereby enhanced the mechanical strength. Samples activated with high NS content $(85 \%)$ revealed better results $(3.4 \mathrm{MPa}$ ) than those prepared with $50 \% \mathrm{NS}$ content $(0.67 \mathrm{MPa})$.

Flexural strength: In this study, prisms prepared with different NS content and tested with three points load. Figure 9 presents the effects of NS content on the flexural strength of GPM after 3,7 and 28 days. The samples were prepared with high NS content showed better results in comparison to the samples prepared with low NS content. This is because of the reaction among $\mathrm{CaO}$ and $\mathrm{SiO}_{2}$ that subsequently formed CSH. Samples prepared with $85 \%$ NS content showed higher flexural strength (5.6 MPa) compared to the samples prepared with $50 \%$ content which display 0.96 MPa. All the samples show increase in flexural strength with increase NS content.

\section{CONCLUSION}

Effect of sodium silicate solution content on setting characteristics and mechanical properties of geopolymer mortar was thoroughly investigated. Multi blend Granulated Blast Furnace Slag (GBFS), Fly Ash (FA) Waste Ceramic (WC) and Waste Glass Bottle (WGB) based geopolymer mortar were studied. Waste materials were activated by using an alkali solution prepared by mixed Sodium Silicate (NS) with sodium hydroxide (NH). Seven mixtures of Geo Polymer Mortar (GPM) were prepared with different sodium silicate content (NS) 50, 60,
$65,70,75,80$ and 85 . Sodium hydroxide concentration, binder to aggregate ratio and solution to binder content were fixed for all mixtures with $6 \mathrm{M}, 1.5$ and 0.35 , respectively. The following conclusion can be withdrawn:

- Increase sodium silicate reduced the initial and final setting time

- Increase silicate content contributed to reduce workability of GPMs

- Increase NS content increases compressive, tensile and flexural strength

- The workability, measured in terms of the flow of mortars, decreased with increase NS content

- Increase sodium silicate content enhances microstructure and increase the density and strength of GPMs

- Water absorption decreases with increased sodium silicate content

\section{REFERENCES}

Al Bakri Abdullah, M.M., H. Kamarudin, O.A. Abdulkareem, C.M.R. Ghazali and A.R. Rafiza et al., 2012. Optimization of alkaline activator/fly ash ratio on the compressive strength of manufacturing fly ash-based geopolymer. Appl. Mech. Mater., 110: 734-739.

Anonymous, 2010. Standard test method for flow of hydraulic cement mortar. ASTM International, West Conshohocken, Pennsylvania, USA.

Bakharev, T., 2006. Thermal behaviour of geopolymers prepared using class F fly ash and elevated temperature curing. Cem. Concr. Res., 36: 11341147.

Castel, A. and S.J. Foster, 2015. Bond strength between blended slag and Class F fly ash geopolymer concrete with steel reinforcement. Cem. Concr. Res., 72: 48-53.

Chen-Tan, N.W., A. Van Riessen, C.V. Ly and D.C. Southam, 2009. Determining the reactivity of a fly ash for production of geopolymer. J. Am. Ceram. Soc., 92: 881-887.

Deja, J., 2003. Properties of activated pastes containing metakaolin and other mineral additives. Proceedings of the 11th International Congress on the Chemistry of Cement (ICCC), May 11-16, 2003, Durban, South Africa, pp: 832-42.

Duxson, P., A. Fernandez-Jimenez, J.L. Provis, G.C. Lukey and A. Palomo et al., 2007. Geopolymer technology: The current state of the art. J. Mater. Sci., 42: 29172933. 
Fernandez-Jimenez, A., A. Palomo and M. Criado, 2005. Microstructure development of alkali-activated fly ash cement: A descriptive model. Cem. Concr. Res., 35: 1204-1209.

Fernandez-Jimenez, A., J.G. Palomo and F. Puertas, 1999. Alkali-activated slag mortars: Mechanical strength behaviour. Cem. Concr. Res., 29: 1313-1321.

Gordon, M., J. Bell and W.M. Kriven, 2005. Comparison of Naturally and Synthetically Derived, PotassiumBased Geopolymers. In: Advances in Ceramic Matrix Composites X, Singh, J.P., N.P. Bansal and W.M. Kriven (Eds.). Wiley, Hoboken, New Jersey, USA., ISBN:9781574981865, pp: 95-97.

Gupta, P.K., Z.A. Khaudhair and A.K. Ahuja, 2016. A new method for proportioning recycled concrete. Struct. Concr., 17: 677-687.

John, V.M., 1995. [Slag cements activated with sodium silicates]. Ph.D Thesis, University of Sao Paulo, Sao Paulo, Brazil. (In Portuguese)

Katz, A., 1998. Microscopic study of alkali-activated fly ash. Cem. Concr. Res., 28: 197-208.

Mo, K.H., U.J. Alengaram and M.Z. Jumaat, 2016. Structural performance of reinforced geopolymer concrete members: A review. Constr. Build. Mater., 120: $251-264$.

Ng, T.S., Y.L. Voo and S.J. Foster, 2012. Sustainability with Ultra-High Performance and Geopolymer Concrete Construction. In: Innovative Materials and Techniques in Concrete Construction, Fardis, M.N. (Ed.). Springer, Berlin, Germany, ISBN:978-94-0071996-5, pp: 81-100.

Obonyo, E., E. Kamseu, U. Melo and C. Leonelli, 2011. Advancing the use of secondary inputs in geopolymer binders for sustainable cementitious composites: A review. Sustainability, 3: 410-423.
Pacheco-Torgal, F., J. Castro-Gomes and S. Jalali, 2008. Alkali-activated binders: A review: Part 1. Historical background, terminology, reaction mechanisms and hydration products. Constr. Build. Mater., 22: 13051314.

Provis, J.L. and J.S.J. Van Deventer, 2009. Geopolymers: Structures, Processing, Properties and Industrial Applications. CRC Press, Boca Raton, Florida, Pages: 441.

Puertas, F. and A. Fernandez-Jimenez, 2003. Mineralogical and microstructural characterisation of alkaliactivated fly ash/slag pastes. Cem. Concr. Compos., 25: $287-292$.

Sagoe-Crentsil, K., 2009. Role of oxide ratios on engineering performance of fly-ash geopolymer binder systems. Ceram. Eng. Sci. Proc., 29: 175-184.

Skvara, F., J. Slosar, J. Bohunek and A. Markova, 2003. Alkali-activated fly ash geopolymeric materials. Proceedings of the 11th International Congress on the Chemistry of Cement (ICCC), May 11-16, 2003, Cement and Concrete Institute, Durban, South Africa, pp: $1-10$.

Sofi, M., J.S.J. Van Deventer, P.A. Mendis and G.C. Lukey, 2007. Engineering properties of inorganic polymer concretes (IPCs). Cem. Concr. Res., 37: 251 257.

Standard ASTM., 2012. Standard test method for compressive strength of hydraulic cement mortars. ASTM International, West Conshohocken, Pennsylvania, USA.

Van Jaarsveld, J.G.S., J.S.J. Van Deventer and G.C. Lukey, 2003. The characterisation of source materials in fly ash-based geopolymers. Mater. Lett., 57: 1272-1280.

Yang, L.Y., Z.J. Jia, Y.M. Zhang and J.G. Dai, 2015. Effects of nano- $\mathrm{TiO}_{2}$ on strength, shrinkage and microstructure of alkali activated slag pastes. Cem. Concr. Compos., 57: 1-7. 